\title{
Mechanical and Morphological Properties of Films Based on Ultrasound Treated Titanium Dioxide Dispersion/Natural Rubber Latex
}

\author{
Stephen Shaibu Ochigbo ${ }^{1, *}$, Adriaan Stephanus Luyt ${ }^{2}$ \\ ${ }^{1}$ Department of Chemistry, Federal University of Technology, P.M.B. 65 Minna, 920001, Nigeria \\ ${ }^{2}$ Department of Chemistry, University of the Free State (Qwaqwa Campus), Phuthaditjhaba, Private Bag X13, 9866, South Africa
}

\begin{abstract}
Titanium dioxide dispersion was sonicated as an attempt to reduce its particle sizes and thereafter used as fillers in making natural rubber (NR) composite films. Fillers of reduced particle sizes, owing to enhanced surface areas and aspect ratios, usually result in unique property improvements. The reinforcing effects of untreated and sonicated samples of the fillers were, therefore, compared through the measurement of tensile properties of the dry films. Results, however, indicated a monotonic decrease in moduli with filler content, contrary to behaviour due to conventional fillers, but showed improvement in both elongation at break and tensile strength data at low filler concentration (2phr), and thereafter a decrease in the trend. The affinity between the filler and matrix was examined using the composite theory of Einstein. Theoretical prediction of Young's moduli from this was compared against experimental data and it was found that there was certain level of interfacial interaction.
\end{abstract}

Keywords Dispersion; Untreated and Sonicated Samples; Fillers; Composite Theory of Einstein; Interfacial Interaction; Films

\section{Introduction}

Natural rubber (NR) latex is tapped naturally from the Hevea Brasiliensis tree, which is a species of rubber tree indigenous to Brazil. Physically, it is a cloudy, white liquid, similar in appearance to cow's milk with a density of 0.980 $\mathrm{g} / \mathrm{cm}^{3}$ or thereabouts and containing, one part rubber particles and another, non-rubber particles suspended in water. Typically, the basic constituents of the latex are as shown in Table I. Changes in season, soil, tapping methods, weather, etc., however, usually exhibits wide variation in the composition of the natural latex. Immediately after the tapping, the latex is usually mixed with ammonia solution to preserve it against bacterial attack and also to prevent solidification (coagulation). The rubber particles (the elastic component sought in all NR products) in the latex are of varying sizes with diameter ranging from 50 to 400 millimicrons. Structurally, natural rubber is a polymer of isoprene in cis configuration thus containing one olefinic double bond[1-4]. Natural rubber is a flexible raw material in the sense that it possesses the ability to be easily modified by the addition of fillers, while retaining its characteristic processing ease, to

* Corresponding author:

stephen_ochigbo@yahoo.com (Stephen Shaibu Ochigbo)

Published online at http://journal.sapub.org/cmaterials

Copyright (C) 2011 Scientific \& Academic Publishing. All Rights Reserved yield materials suitable for various applications. Major products manufactured from the latex include latex paints, water-borne coatings, and water-proof sheeting materials as well as dipped products such as gloves and condoms, which are known for their excellent barrier protection against microorganisms including bacteria and viruses, as well as infectious diseases.

Titanium dioxide is an inexpensive, nontoxic and photostable inorganic material, which has good optical and photocatalytic properties for many applications. Due to its high refractive index and ability to reflect and refract or scatter light more effectively than any other pigment, titanium dioxide has for many years served and is still serving as a white pigment. It is also used to provide protection against UV effect because it is capable of absorbing UV light. The surface of titanium dioxide particles is hydrophilic due to presence of hydroxyl groups[6]. The inclusion of inorganic fillers in polymer usually results in improvement in strength, toughness, processability, dimensional stability, wear and lubrication properties, and in some cases resistance to thermal and UV radiation of the matrix. The effect of fillers on properties of the composites depends on the concentration, particle size, shape and the interaction of the fillers with the matrix[5]. Among these factors, the role of particle size seems to occupy a significant place in the determination of properties of polymer composites.

Several studies have revealed that unique improvements in 
thermal stability, mechanical strength, hydrophilicity and viscoelasticity are obtained in different types of polymer matrix by the inclusion of nanosized particles of $\mathrm{TiO}_{2}$ [7-10]. Consequently, methods for achieving particle size reduction of inorganic materials, including $\mathrm{TiO}_{2}$ particles, meant for compounding polymer matrixes are being vigorously investigated. A review of the variety of methods that have so far been developed has been presented[11], namely sol-gel process, hydrothermal methods, solvothermal methods, emulsion precipitation and, recently a facile flame method. In this work, the use of ultrasound treatment, as an example of hydrothermal method, is employed to attempt particle size reduction in $\mathrm{TiO}_{2}$ dispersion prior to blending with NR latex. Majority of inorganic fillers are introduced into polymers in form of dry powders. In the present paper, the filler is an aqueous dispersion of $\mathrm{TiO}_{2}$ and the decision is based on the convenience involved in blending it with NR latex which, like the former, is also an aqueous system. This is called latex compounding method (LCM). This is a simple but efficient technique capable of enhancing the compatibility between the two components. As far as available literature in the field is concerned, there seems not to be any reported investigation of this system in particular as presented in this paper.

Table 1. Composition of NR latex[3]

\begin{tabular}{ll}
\hline Constituents & \% Composition \\
\hline Rubber particles & $30.0-40.0$ \\
Protein & $2.0-3.0$ \\
Water & $55.0-65.0$ \\
Steril glycosides & $0.1-0.5$ \\
Resins & $1.5-3.5$ \\
Ash & $0.5-1.0$ \\
Sugars & $1.0-2.0$ \\
\hline
\end{tabular}

\section{Experimental}

\subsection{Materials}

Titanium dioxide dispersion (XK, XERACOLOUR WHITE) used for this study was kindly supplied from ICC Pty. Ltd., Midrand, 1665 South Africa. It is a white coloured mixture supplied as an easily pourable paste for volumetric dispensing, and mainly intended for use in decorative paint systems. Ammonia-stabilized normal latex was obtained from the Rubber Research Institute of Nigeria, Benin City having determined total solids contents of 48 wt. \%. The properties of the Titanium dioxide dispersion used are shown in Table II below. The material was used as received.

\subsection{Sonication}

Ultrasonic treatment of the dispersion was first carried on three batches of samples of $\mathrm{TiO}_{2}$ dispersions (each $40 \mathrm{gm}$ ) contained in beakers for $24 \mathrm{~h}, 48 \mathrm{~h}$, and $96 \mathrm{~h}$, respectively using a UMC10 (Ultrasonic Manufacturing Company Pty Ltd., Krugersdorp 1745, South Africa) ultrasonic liquid processor operating on a voltage of $220 \mathrm{~V}$ with a $50 \mathrm{~Hz}$ converter and adapter for time adjustment. All beakers were covered with aluminum foil to prevent moisture evaporation from the samples during the treatment period.

Table 2. Characteristics of the $\mathrm{TiO}_{2}$ dispersion used*

\begin{tabular}{|c|c|}
\hline Properties & Values \\
\hline Density @ $25^{\circ} \mathrm{C}$ & $1.90-2.00 \mathrm{~g} / \mathrm{cm}^{3}$ \\
Viscosity @ $25^{\circ} \mathrm{C}$ & $95-100 \mathrm{KU}$ \\
$\mathrm{pH}$ & $7.0-8.5$ \\
Volume solids & $31.4 \%$ \\
Pigment & $56.4 \%$ \\
\hline
\end{tabular}

*Source: Manufacturer

\subsection{Preparation of Composite Films}

Latex (16gm) was taken into a beaker and various preweighed $\mathrm{TiO}_{2}$ dispersion (the untreated as well as sonicated samples) was added respectively with vigorous stirring so as to yield composites. Amounts of 2, 4 and $6 \mathrm{pphr}$ (parts of the solid pigment per hundred parts of rubber) were used, giving a total number of 12 preparations. The mixing process was carried out under fast speed stirring adjustment with magnetic hot plate/stirrer (FMH Instruments) at ambient temperature $\left(\approx 25^{\circ} \mathrm{C}\right)$ until a visually homogeneous phase was obtained. Thin films were then prepared from this mixture by casting on non-sticky transparent polyester sheets pasted on rectangular glass sheets. Immediately afterwards, the glass sheets with the wet films were transferred into convection oven set at $50^{\circ} \mathrm{C}$ for drying for about 18 hours. At the end of the period, the resulting dry films were allowed to cool to ambient temperature. Specimens for subsequent analysis were cut from the films into required shapes, depending upon the type of test, while still attached to the polyester substrate. The adhesive force between the substrate is minimal enough to allow easy separation of the composite film from the substrate, without causing any deformation to the prepared films, by application of a gentle and gradual peeling force.

\subsection{Characterizations}

Particle size analysis of both the untreated and sonicated $\mathrm{TiO}_{2}$ dispersions was carried with a Malvern Mastersizer Hydro 2000MY instrument in order to determine the extent of particle reduction achieved by the ultrasound treatment process.

Dumb-bell shaped test specimens with a gauge width of $5.08 \mathrm{~mm}$ were obtained from the films using a punch. Tensile property measurements were determined with free films in a standard testing procedure according to ASTM D632-882, using a tensile tester (HOUNSFIELD, Model H5KS) at crosshead speed of $20 \mathrm{~mm} \cdot \mathrm{min}^{-1}$ at ambient temperature $\left(25^{\circ} \mathrm{C}\right)$. Five specimens were measured for each sample and the averaged values were reported with standard deviation showing the error range.

\section{Results and Discussion}

Fig. 1 shows the particle size distribution of the $\mathrm{TiO}_{2}$ dispersion in percentage of particle volume for different 
hours of sonication. The untreated sample $(0 \mathrm{~h})$ as well as samples after $24 \mathrm{~h}$ and $96 \mathrm{~h}$ of sonication, respectively, presents a bimodal particle size distribution each, one in the range of submicron-sized particles (between $0-1.0 \mu \mathrm{m}$ ) and the other in the range of micron-sized particles $(\mu \mathrm{m})$.

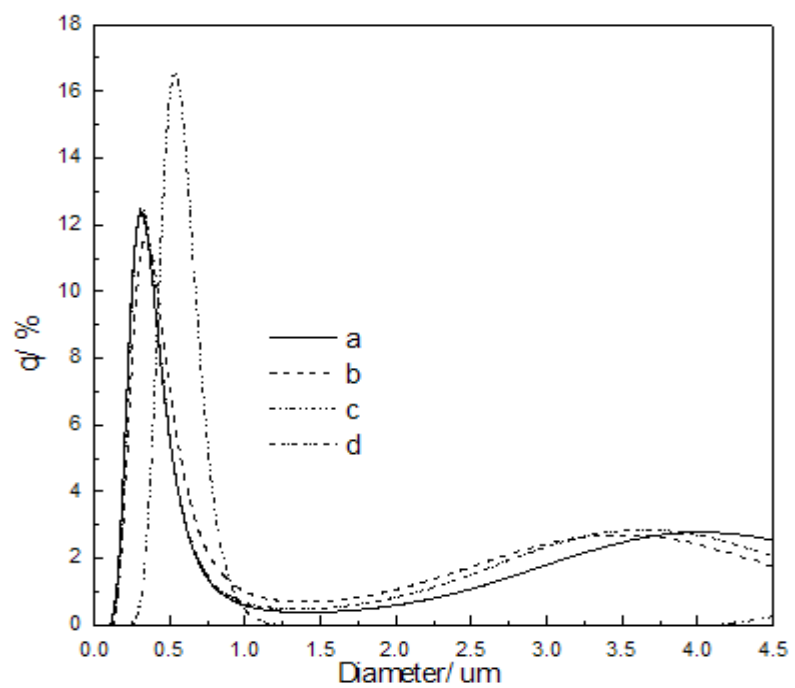

Figure 1. Particle size distribution of the particles at different hours of sonication (a) untreated $\mathrm{TiO}_{2}$, (b) 24h sonicated, (c) 48h sonicated, (d) $96 \mathrm{~h}$ sonicated

As seen, the volume percentages of the particles in the submicron-sized range in the case of both oh and 96h sonication times not only synchronized but both also are higher than that of $24 \mathrm{~h}$ sonication within the quoted particle-sized range. Maxima in the range for submicron-sized and micron-sized particles were at $\sim 0.30$ and $3.90 \mu \mathrm{m}$ for untreated sample, 0.34 and $3.41 \mu \mathrm{m}$ for sample after $24 \mathrm{~h}$, and 0.30 and $3.90 \mu \mathrm{m}$ for sample after $96 \mathrm{~h}$ sonication times, respectively. Only one maximum is recorded for $48 \mathrm{~h}$ sample and is at 0.51 $\mu \mathrm{m}$. For each of the three samples having two populations of particles, it is generally observed that the volume percentage of the particles smaller than $1 \mu \mathrm{m}$ is significantly higher as compared with the volume percentage in the range of larger ones. Only the sample sonicated for $48 \mathrm{~h}$ displayed a single maxima particle size distribution falling within the range of submicron-sized particles. The presence of two populations of particles observed, in each case, for untreated, after $24 \mathrm{~h}$ and $96 \mathrm{~h}$ sonication evidenced co-existence of narrow-sized as well as aggregated particles for these samples. The results show that sonication after $24 \mathrm{~h}$ and that after $96 \mathrm{~h}$ produced the same type of sized ranged particles as those of the untreated sample. While the situation after $24 \mathrm{~h}$ could indicate that the particles of the dispersion at this time have not been sufficiently sonicated to cause the expected particle reduction, the situation after $96 \mathrm{~h}$ could on the other hand be attributable to particle re-aggregation of broken particles arising from prolonged sonication time. There is literature report to justify that particle aggregation occurs partly after a prolonged sonication[12-16]. Consequently, it is reasonable to state that sonication carried out after $48 \mathrm{~h}$ under our experimental conditions represents the practical limit for ob- taining submicron narrow-sized particles. All the others samples each has two different populations of particle sizes, distributed between the sub-micron size and the micron sized ranges of the particles. Based on this particle size analysis, samples obtained after $48 \mathrm{~h}$ sonication was selected to illustrate the change in mechanical properties with filler concentration.

Young's modulus is the stiffness (the ratio of the stress to strain) of a material at the elastic stage of a tensile test. Therefore, the ratio is obtained from the linear region of the stress-strain curve[5,17]. A number of reports[18-27] have shown that Young's modulus increases for a polymer by the addition of either micro- or nano-particles since rigid inorganic particles generally have a much higher stiffness than polymer matrices. Additional reason stated in support of increased modulus in polymer matrix due to filler infusion is that the ratio of the filler modulus to polymer modulus for all of the various filler-polymer combinations exceeds 30: 1[5]. In this report, the Young moduli were calculated based on the values of stress and strain bounded between 1 and $5 \%$ strain of the tensile data points. This region in the curve was seen to best represent the bounds where elastic behaviour was optimized. Fig. 2 shows the dependence of Young's modulus on filler concentration of the composites.

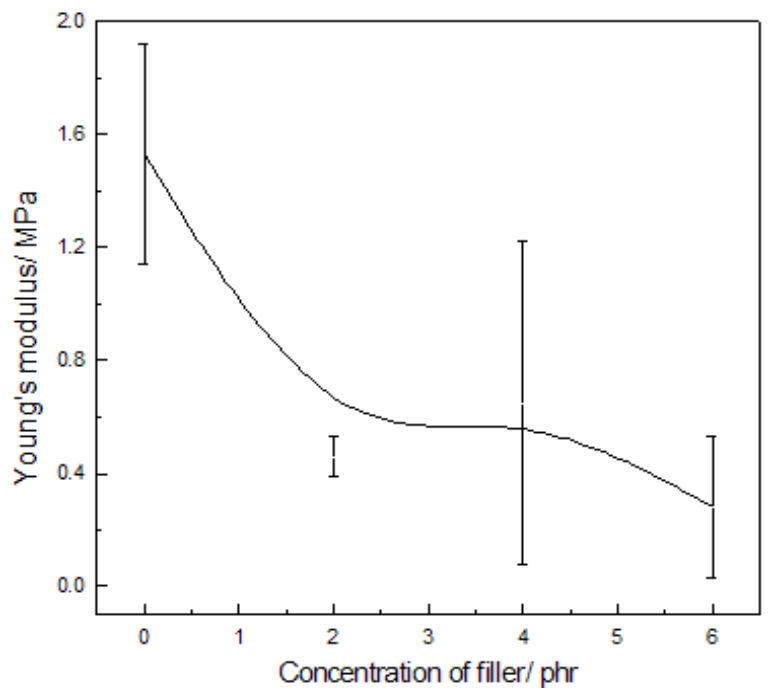

Figure 2. Composition dependence of Young's modulus of $48 \mathrm{~h}-\mathrm{TiO}_{2}-\mathrm{NR}$ composites

As seen, the behaviour is contrary to trend that is familiar with conventionally filled polymer composites[18-27]. Instead of observing the usual consistent increases in modulus, result shows an S-type monotonic decrease in Young's modulus with increasing particle loading. In order to explain this result justifiably, it is important to preview the factors that are linked to modulus. The increase in modulus due to addition of fillers is attributed to the various parameters of the fillers added to the polymer. They include the aspect ratio of the filler[5,17], the orientation of the fillers, interfacial interaction and the nature of the failure[5]. From the studies reported[18,24,28-36], it seems that there is a critical particle size, usually in nanoscale, above which there is no effect on 
composite modulus. When the particle size is below this critical value, the effect on composite modulus is more significant. Unfortunately, the magnitude of this critical particle size cannot be predicted a priori for it depends on the particle, matrix and particle/matrix adhesion[17]. It can, therefore, only be attained by chance. There are studies that have shown, contrary to what has been suggested above, that interfacial interaction or adhesion did not have any significant effect on modulus [19,37]. This view was also held by Fu et al.[17] based on the argument that Young's modulus is measured at relatively low deformation and as such there is insufficient dilation to cause interface separation. Thus, the adhesion strength does not noticeably affect the elastic modulus. Following from the above information, these authors were strongly inclined to attribute the present unusual behaviour to failure of the ultrasound treatment procedure employed in achieving the particle size reduction of the fillers to the size level that is favourable for enhancement of modulus with the filler loadings. The particle size distribution of this filler, as shown in Fig. 1, suggests that these particles were most likely too large to be able to bring about any improvements in moduli. Another possible reason for the observed decreasing modulus with loading might not be unconnected with the style of orientation of the fillers in the matrix. In the formation of polymer composites, the mineral fillers are applied, in most cases, in form of solid powders. This method of addition tends to favour alignment of fillers in the direction of applied processing stress thus, in majority of cases, giving rise to the kind of morphology with improved Young's modulus in the composite more than the pure polymer. Here, the filler $\left(\mathrm{TiO}_{2}\right.$ dispersion) was in the form of easily pourable paste and applied as provided for the convenience of mixing with the NR latex in order to prepare the composites by casting method. Certainly, this method of processing will produce composites in which the fillers are not likely to have the kind of orientation in the matrix that increases modulus with filler loading. Moreover, in this stage, tendency for particle agglomeration will be significantly higher with increasing filler loading and, hence, reducing moduli simultaneously.

The tensile strength of a material is defined as the maximum stress that the material can sustain under uniaxial tensile loading. For micro- and nano-particulate composites, this is dependent upon the effectiveness of stress transfer between matrix and fillers[17]. The tensile strength of a filled polymer depends strongly on local polymer-filler interactions and somewhat on such other factors, as the geometry, modulus, particle size distribution and concentration of filler. Effective stress transfer which is the basis of the strength of two-phase composite materials is controlled by the particle/matrix interfacial adhesion. For poorly bonded particles, the stress transfer at the particle/polymer interface is inefficient. Discontinuity in the form of debonding exists because of non-adherence of particle to polymer. Thus the particle cannot carry any load and the composite strength decreases with increasing particle loading. However, for composites containing well-bonded particles, addition of particles to a polymer will lead to an increase in strength especially for nanoparticles with high surface areas[17]. Two general tensile strength-filler concentration responses are known, namely the upper bound and lower bound ones. The upper bound response assumes strong adhesion between the polymer and filler, while the lower bound response assumes weak, or no, adhesion between the polymer and filler materials. Most particulate-filled polymers are said to fall somewhere between these two responses[5]. Fig. 3 presents the results of tensile strength of the composites with filler content.

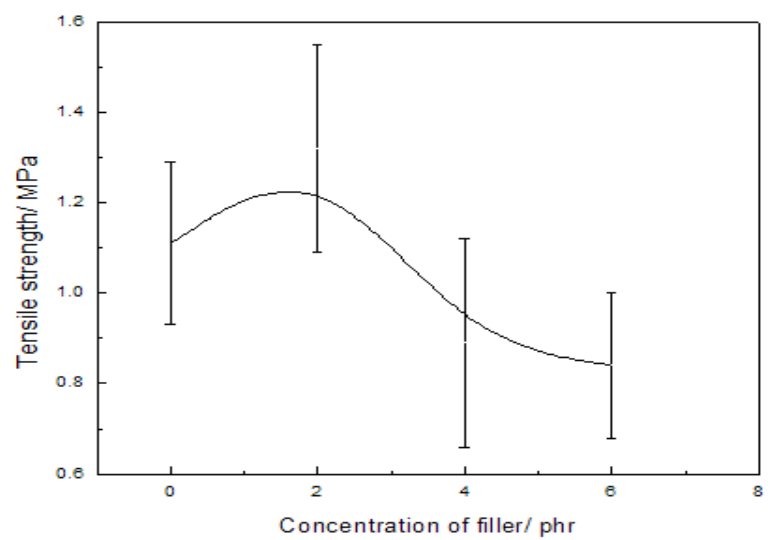

Figure 3. Composition dependence of tensile strength of $48 \mathrm{~h}-\mathrm{TiO}_{2}-\mathrm{NR}$ composites

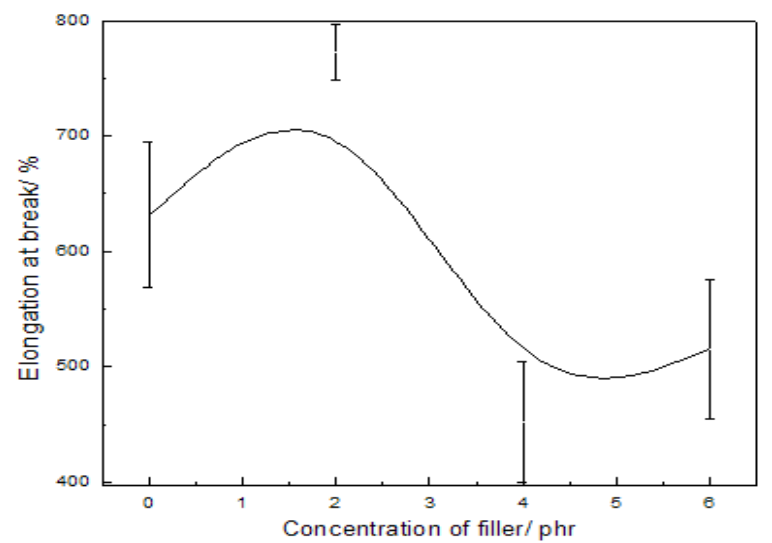

Figure 4. Composition dependence of elongation at break of $48 \mathrm{~h}-\mathrm{TiO}_{2}-\mathrm{NR}$ composites

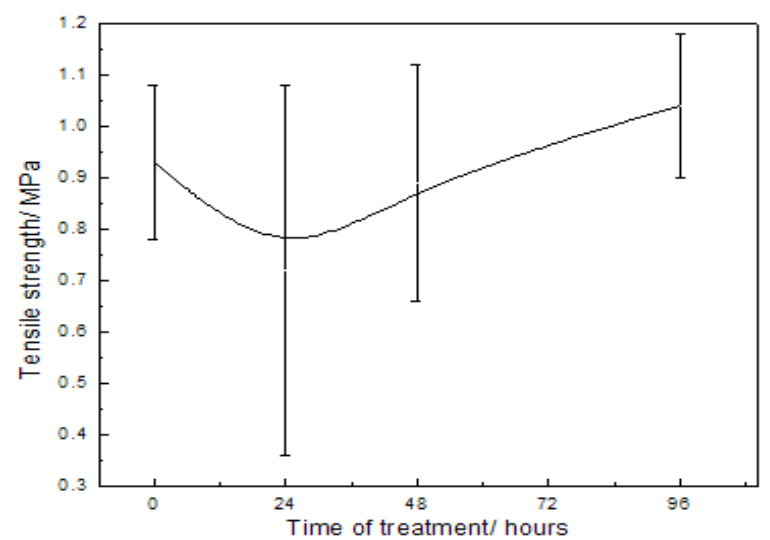

Figure 5. Effect of sonication time on tensile strength of $\mathrm{TiO}_{2}-\mathrm{NR}$ composites 
It is observed from this figure a bell-shaped curve with $\mathrm{TiO}_{2}$ loading. The surface of $\mathrm{TiO}_{2}$ particles is hydrophilic due to the presence of hydroxyl groups[38]. Thus, there could be hydrogen bonding interaction in between $\mathrm{TiO}_{2} / \mathrm{NR}$ interface for effective stress transfer. This, therefore, resulted in the observed increased strength. A fall in this parameter took place if the filler content is above $2 \mathrm{phr}$, which should be due to particle aggregation taking over from this point as the particle content increases. A similar pattern of results was obtained in Fig. 4 in the plots of elongation at break versus $\mathrm{TiO}_{2}$ content.

Elongation at break values denotes the maximum extension of the samples while in tension. By incorporating the fillers this can be enhanced. The elongation at break values depends on the filler/matrix interaction[5]. The same explanation presented in respect of tensile strength also applies here. Both these results indicate that the filler and the matrix have some interaction and $\mathrm{TiO}_{2}$ content of $2 \mathrm{phr}$ represents optimum amount of filler for best performance of the respective properties.

The change of the above tensile properties was, nevertheless, measured as a function of time of treatment. The results of tensile strength, elongation at break and Young's modulus are shown in Figs. 5, 6, and 7, respectively.

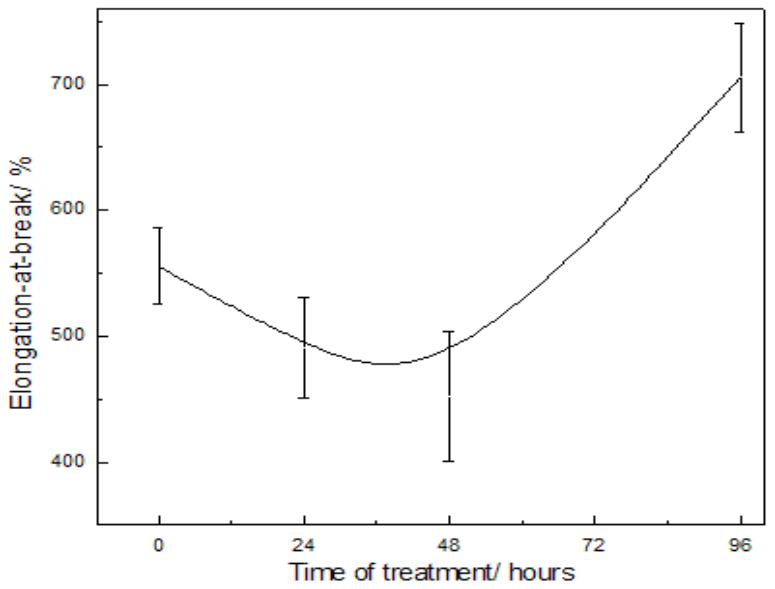

Figure 6. Effect of sonication time on elongation-at-break of $\mathrm{TiO}_{2}-\mathrm{NR}$ composites

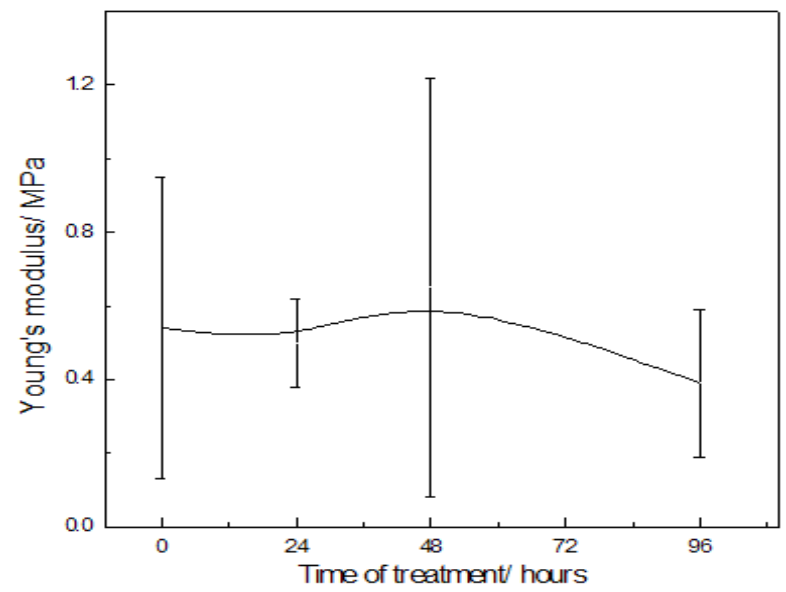

Figure 7. Effect of sonication time on Young's modulus of $\mathrm{TiO}_{2}-\mathrm{NR}$ composites
Both tensile strength and elongation at break again display similar pattern of change of properties with hours of sonication. This is not surprising because both parameters are affected by the same factors. Initial decrease in either tensile strength or elongation at break with time of treatment was shown with a minimum at the $24 \mathrm{~h}$. After this a gradual rise was observed with hours of treatment such that the values at $96 \mathrm{~h}$ are higher than untreated sample (0h). The results, therefore, prove that ultrasound treatment have significant effect on both tensile and elongation at break. Since the surface of $\mathrm{TiO}_{2}$ contains presence of hydroxyl groups[38], it is suggested that dehydroxylation process takes place due to the ultrasound treatment resulting in increased concentration of hydroxyl groups favouring $\mathrm{TiO}_{2} / \mathrm{NR}$ interfacial hydrogen bonding with increased time of treatment. Thus, tensile strength and elongation at break which relies on effective stress transfer created by such interface bonding correspondingly increased. The fall in these properties at $24 \mathrm{~h}$ is inexplicable at the level of this present investigation. Further analysis, particularly focusing on morphological changes during treatment, is what might be required to unravel the cause. The effect of time of treatment on the Young's modulus (Fig. 7) shows that there is insignificant relationship between them. The trend shown can be approximated to a plateau if the small broad peak at $48 \mathrm{~h}$ is ignored. The behaviour at this point can be due to size effect of the particles of $\mathrm{TiO}_{2}$. Recall that in Fig. 1, the particle size distribution of the fillers during $48 \mathrm{~h}$ treatment is a unimodal sharp peak representing narrow size particles. Since particle size affects modulus significantly, we conclude that the little enhancement in modulus against $48 \mathrm{~h}$ is caused by the uniqueness of the particle size characterizing this stage.

The modulus is the easiest mechanical property to estimate, because it is a bulk property that depends primarily on the geometry, modulus, particle size distribution and concentration of filler. The tensile strength of a filled polymer is more difficult to predict because it depends strongly on local polymer-filler interactions as well as the above factors[5]. In order to evaluate the affinity between the NR matrix and particles of the $\mathrm{TiO}_{2}$ dispersion, the experimental moduli have been compared with prediction values using Einstein's Eq. $[5,39]$ presented below.

$$
\mathrm{E}_{\mathrm{c}}=\mathrm{E}_{\mathrm{m}}\left(1+2.5 \mathrm{~V}_{\mathrm{f}}\right)
$$

Where $\mathrm{E}_{\mathrm{c}}$ and $\mathrm{E}_{\mathrm{m}}$ are the young's modulus of composite and matrix, respectively, and $\mathrm{V}_{\mathrm{f}}$ is the volume fraction of filler. This theoretical prediction, like other similar theories in the literature[5], assumes that matrix and filler have no appreciable degree of interaction. The concentration (phr) of the filler was converted into its equivalent in volume fraction and the theoretical moduli obtained from the equation were plotted with the experimental result in Fig. 8.

It can be seen that the theoretical curve does not fit with the experimental result. Whereby the experimental results agree with theory, it is an indication that the reinforcing action becomes weaker[5]. Therefore, based on this result, we can conclude that there was some interaction between the 
matrix and filler, which also was evidenced from the mechanical properties.

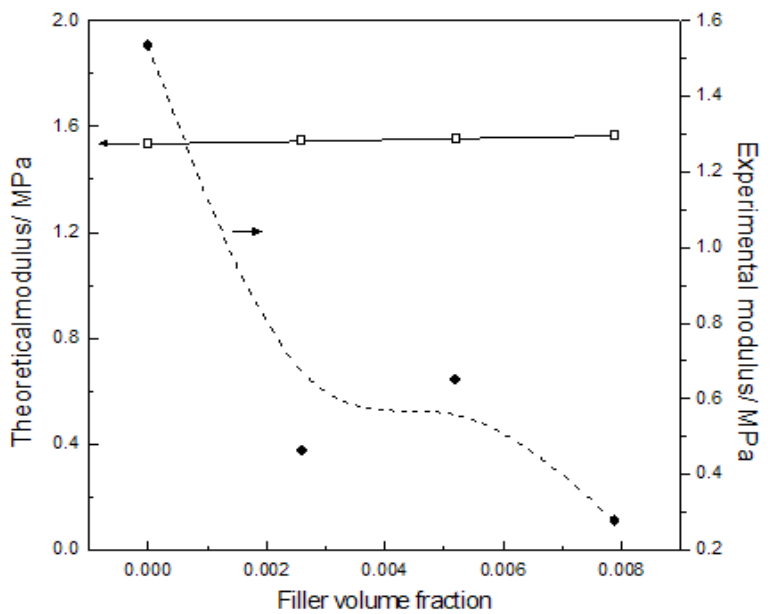

Figure 8. Comparison between theoretical (solid line) and experimental (dash line) moduli based on Einstein's equation

\section{Conclusions}

Ultrasound treatment was carried out with $\mathrm{TiO}_{2}$ dispersion at three different hours of sonication. Particle size analysis of the resulting particles revealed a mixture of unimodal (for 48h) and bimodal ( $24 \& 96 \mathrm{hs}$ ) particle-size distribution. Composites films of NR latex with both treated and sonicated $\mathrm{TiO}_{2}$ were successfully prepared by latex blending under high speed magnetic stirring and cured in a conventional oven for about $18 \mathrm{hs}$. Mechanical properties by tensile measurement as well as prediction of properties using Einstein equation indicated certain level of interfacial interaction in the NR- $\mathrm{TiO}_{2}$ composites. Since NR is a renewable and biodegradable resource, $\mathrm{TiO}_{2}$ is a relatively cheap, photostable and non-toxic inorganic filler compared to such conventional fillers as carbon black and silica, etc, the $\mathrm{NR} / \mathrm{TiO}_{2}$ composites is judged to have great potential for usefulness in the future, especially for manufacture of packaging materials meant for protection of substances against the effect of UV prior to their use, as well as development of surface coatings and related products.

\section{ACKNOWLEDGEMENTS}

Manfred Scriba of CSIR, Pretoria, South Africa is thanked for performing the measurements of particle size analysis. Financial support from National Research Foundation (NRF) of South Africa via the IRDP programme is highly appreciated.

\section{REFERENCES}

[1] Yip, E., and Cacioli, P., 2002, The Manufacture of Gloves from Natural Rubber Latex., J Allergy Clin. Immunol., 110 (2), S3-S14

[2] Popović, R., Milenković, D., Popović, R., Plavšić, M., 2005, Properties of Natural Rubber/Carboxilated Styrene-Butadiene Lattices Blends., Scientific-Technical Review, LV (3-4), 66-69

[3] Jayanthy, T. and Sankaranarayanan, P.E., 2005, Measurement of Dry Rubber Content in Latex Using Microwave Technique., Measurement Science Review, 5 (3), 50-54

[4] Khalid, K.B., and Daud, W. M., 1994, Dielectric Properties of Natural Rubber Latex at Frequencies from 200MHz to 2500 MHz., Journal of Rubber Research Institute of Malaysia 7 (4), 281-289

[5] Selvin, T.P., Kuruvilla, J., Sabu, T., 2004, Mechanical Properties of Titanium Dioxide-Filled Polystyrene Microcomposites., Materials Letters 58, 281-289

[6] Erdem, B., Hunisicker, R. A., Simmons, G.W., Sudo,1 E.D., Dimonie, V.L., El-Aasser, M.S., 2001, XPS and FTIR Surface Characterization of $\mathrm{Tio}_{2}$ Particles Used in Polymer Encapsulation., Langmuir, 17, 2664-2669

[7] Laachachi, A., Cochez, M., Ferriol, M., Lopez-Cuesta, J. M., Leroy, E., 2005, Influence of $\mathrm{TiO}_{2}$ and $\mathrm{Fe}_{2} \mathrm{O}_{3}$ Fillers on the Thermal Properties of Poly (Methyl Methacrylate) (PMMA)., Materials Letters, 59, 36-39

[8] Džunuzović, E., Jeremić, K., Nedeljković, J.M., 2007, In Situ Radical Polymerization Of Methyl Methacrylate in a Solution of Surface Modified $\mathrm{TiO}_{2}$ and Nanoparticles., European Polymer Journal, 43, 3719-3726

[9] Wu, G., Gan, S., Cui, L., Xu, Y., 2008, Preparation and Characterization of PES/TiO ${ }_{2}$ Composite Membranes., Applied Surface Science., 254, 7080-7086

[10] Chatterjee, A., and Islam, M.S., 2008, Fabrication and Characterization of $\mathrm{TiO}_{2}$-Epoxy Nanocomposite., Materials Science and Engineering A, 487, 574-585

[11] Zhao, Y., Li, C., Liu, X., Gu, F., Jiang, H., Shao, W., Zhang, L., He, Y., 2007, Synthesis and Optical Properties of $\mathrm{TiO}_{2}$ Nanoparticles., Materials Letters, 61, 79-83

[12] Delgado, A., and Matijevic, E., 1991, Particle Size Distribution of Inorganic Colloidal Dispersions: A Comparison of Different Techniques., Part. Part. Syst. Charact., 8, 128-135

[13] Pérez-Rodríguez, J.L., Carrera, F., Poyato, J., Pérez-Maqueda, L.A., 2002, Sonication as a Tool for Preparing Nanometric Vermiculite Particles., Nanotechnology, 13, 382-387

[14] Franco, F., Pérez-Maqueda, L.A., Pérez-Rodríguez, J.L., 2004, The Effect of Ultrasound on the Particle Size and Structural Disorder of a Well-Ordered Kaolinite., Journal of Colloid and Interface Science, 274, 107-117

[15] Franco, F., Pérez-Maqueda, L.A., Pérez-Rodríguez, J.L., 2004, Influence of the Particle-Size Reduction by Ultrasound Treatment on the Dehydroxylation Process of Kaolinites., Journal of Thermal Analysis and Calorimetry., 78, 1043-1055

[16] Pérez-Maqueda, L.A., Duran, A., Pérez-Rodríguez, J.L., 2005, Preparation of Submicron Talc Particles by Sonication., Applied Clay Science., 28, 245-255

[17] Fu, S.-Y., Feng, X.-Q., Lauke, B. Mai, Y.-W., 2008, Effects 
of Particle Size, Particle/Matrix Interface Adhesion and Particle Loading on Mechanical Properties of Particulate- Polymer Composites., Composites, Part B 39, 933-961

[18] Zhu, Z.K., Yang, Y., Yin, J. Qi, Z.N., 1999, Preparation and Properties of Organosoluble Polyimide/Silica Hybrid Materials by Sol-Gel Process., J Appl Polym Sci., 73, 2977-2984.

[19] Dekkers, M.E.J., and Heikens, D., 1983, The Effect of Interfacial Adhesion on the Tensile Behavior of Polystyrene-Glass-Bead Composites., J Appl Polym Sci., 28, 3809-3815

[20] Fu, S.Y., and Lauke, B., 1998, Characterization of Tensile Behaviour of Hybrid Short Glass Fibre Calcite Particle ABS Composites., Composite Part A, 29A, 573-583

[21] Fu, S.Y., and Lauke, B., 1997, Analysis of Mechanical Properties of Injection Short Glass Fibre (SGF)/Calcite/ABS Composites., J Mater Sci Technol., 13, 389-396

[22] Eirich, F. R., 1984, Some Mechanical and Molecular Aspects of the Performance of Composites., J Appl Polym Sci Appl Polym Symp, 39, 93-102

[23] Radford, K.C., 1971, The Mechanical Properties of an Epoxy Resin with a Second Phase Dispersion., J Mater Sci., 6, 1286-1291

[24] Spanoudakis, J., and Young, R.J., 1984, Crack Propagation in a Glass Particle-Filled Epoxy-Resin. 1. Effect of Particle-Volume Fraction and Size., J Mater Sci., 19, 473-486

[25] Amdouni, N., Sautereau, H. Gerard, J.F., 1992, Epoxy Composites Based on Glass-Beats. 2. Mechanical-properties., J Appl Polym Sci., 46, 1723-1735

[26] Wang, M., Berry, C., Braden, M. Bonfield, W., 1998, Young's and Shear Moduli of Ceramic Particle Filled Polyethylene., J Mater Sci Mater Med., 9, 621-624

[27] Ou, Y., Yang, F., Yu, Z.Z., 1998, A new conception on the toughness of nylon 6/silica nanocomposite prepared via in situ polymerization., J Polym Sci Part B Polym Phys., 36, 789-795

[28] Xie, X.L., Zhou, X.P. Mai, Y-W., 2005, Dispersion and Alignment of Carbon Nanotubes In Polymer Matrix: A Review., Mater Sci Eng R., 49, 89-112

[29] Nakamura, Y., Yamaguchi, M., Okubo, M. Matsumoto, T.,
1992, Effect of Particle Size on Mechanical Properties of Epoxy Resin Filled with Angular-Shaped Silica., J Appl Polym Sci., 44, 151-158

[30] Zhang, Q, Tian, M., Wu, Y., Lin, G. Zhang, L, 2004, Effect of Particle Size on the Properties of $\mathrm{Mg}(\mathrm{OH})_{2}$-Filled Rubber Composites., J Appl Polym Sci., 94, 2341-2346

[31] Lazzeri, A., Thio, Y.S., Cohen, R.E., 2004, Volume Strain Measurements on $\mathrm{CaCO}_{3} /$ Polypropylene Particulate Composites: The Effect of Particle Size., J Appl Polym Sci., 91, 925-935

[32] Suprapakorn, N., and Dhamrongvaraporn, S.S., 1998, Effect of $\mathrm{CaCO}_{3}$ on the Mechanical and Rheological Properties of a Ring-Opening Phenolic Resin: Polybenzoxazine., Polym Compos., 19, 126-132

[33] Singh, R.P., Zhang, M., Chan, D., 2002, Toughening of a Brittle Thermosetting Polymer: Effects of Reinforcement Particle Size and Volume Fraction., J Mater Sci., 37, 781-788

[34] Lange, F.F., and Radford, K.C., 1971, Fracture Energy of an Epoxy Composite System., J Mater Sci., 6, 1197-1203

[35] Ji, X.L., Jing, J.K., Jiang, B.Z., 2002, Tensile Modulus of Polymer Nanocomposites., Polym Eng Sci., 42, 983-993

[36] Mishra, S., Sonawane, S.H. Singh, R.P., 2005, Studies on Characterization of Nano $\mathrm{Caco}_{3}$ Prepared by the In Situ Deposition Technique and its Application in PP-Nano $\mathrm{CaCO}_{3}$ Composites., J Polym Sci Part B Polym Phys., 43, 107-113

[37] Douce, J., Boilot, J.P., Biteau, J., Scodellaro, L. Jimenez, A., 2004, Effect of Filler Size and Surface Condition of Nano-Sized Silica Particles in Polysiloxane Coatings., Thin Solid Films, 466, 114-122

[38] Sahu, S., and Broutman, L.J., 1972, Mechanical Properties of Particulate Composites., Polym Eng Sci., 12, 91-100

[39] Erdem, B., Hunisicker, R.A., Simmons, G.W., Sudol, E.D., Dimonie, V.L. El-Aasser, M.S., 2001,. XPS and FTIR Surface Characterization of $\mathrm{TiO}_{2}$ Particles Used in Polymer Encapsulation., Langmuir, 17, 2664-2669

[40] Murariu, M., Ferreira, A., Da, S., Degée, P., Alexandre, M., Dubois, P., 2007, Polylactide Compositions. Part 1: Effect of Filler Content and Size on Mechanical Properties of PLA/Calcium Sulfate Composites., Polymer, 48, 2613-2618 